\title{
The Particle Swarm Optimization Algorithm of Three- state Reliability Redundancy Allocation Problem
}

\section{Dongkui $\mathbf{L i}^{123}$}

Journal Editorial Department of Baotou Teachers College, Baotou 014030, China

E-mail: 165380380 eqq. com

This paper studies the three-state series-parallel (S-P) devices network reliability redundancy allocation problem (RAP) whose different components is paralleled, and the objective function is maximized with cost and weight constraints. A new model is built. A new algorithm is constructed by using an objective function, that is, the discrete particle swarm optimization algorithm with compression coefficient to solve the RAP problem. The algorithm is tested by two instances of the problem with MATLAB programming. As shown by the results, under the usually initial solution conditions, the particle swarm optimization algorithm can converge in each run and solve the system; at the same time, the algorithm is compared with the traditional simulated annealing algorithm, ant colony algorithm and genetic algorithm. The particle swarm optimization algorithm features advantages of easy programming and efficient convergence to the system optimal solution.

CENet2017

22-23 July, 2017

Shanghai, China

\footnotetext{
${ }^{1}$ Speaker

${ }^{2}$ This sudy is supported by the Yinshan scholars training plan of the Baotou Teachers College.

${ }^{3}$ Correspongding author
} 


\section{Introduction}

The two-state network system reliability redundancy allocation problem (RAP) in engineering as proposed is the nonlinear integer programming problem. Extensive researches have been carried out in literature and many specific optimization models have abstracted and put forward a number of methods to find the optimal solution, such as dynamic programming, branch and bound method, linear programming method, lagrange multiplier method, heuristic method, genetic algorithm ant colony algorithm [1-3]. For the three-state devices network reliability optimization problem, as the system components and system have two failure modes, the three-state system reliability showed different regularity in comparison with the two-state and the general optimization problem is NP-Hard, has attracted more and more researchers [47].

The genetic algorithm, the ant colony algorithm and the particle swarm optimization algorithm as well as other intelligent optimization algorithms have get better results in solving specific reliability optimization problem, and the intelligent optimization algorithm shows great potential in dealing with reliability optimization problems [8-16]. But there are a lot of difficulties for the intelligent algorithm in solving the reliability optimization problem, for example, the choice of parameters have no specific regularity or initial solution selection difficult. As the solutions search path is too complex and some algorithm execution time is too long, easy to fall into local optimal solution, etc. [17-20].

In this paper, a three-state devices network reliability redundancy allocation problem (RAP) model is constructed, a new discrete particle swarm optimization algorithm with contraction coefficient is designed, and the simulation is carried out for problem instances.

\section{Models and Solution Structure}

The following discussion assumes that (1) components and systems have three states, namely, the normal working mode, the open failure and shorted failure mode (2) the the cost, the weight of components, the shorted failure and the open failure mode probability of components are known, and the open failure and shorted failure probability of components is statistically independent (3) the cost and weight of the system is a linear function of the cost and weight of the component (4) the component cannot be repaired. The mathematical model of reliability redundancy allocation problem in the three-state devices S-P network is as follows:

$$
\begin{aligned}
& \quad \max R_{s}=1-Q_{s}-S_{s}=\prod_{i=1}^{n}\left(1-\prod_{j=1}^{a_{i}} q_{i j} x_{i j}\right)-\prod_{i=1}^{n}\left(1-\prod_{j=1}^{a_{i}}\left(1-S_{i j}\right)^{x_{i j}}\right) ; \\
& \text { s.t. } C=\sum_{i=1}^{n} C(i) \leqslant C_{0}, W=\sum_{i=1}^{n} W(i) \leqslant W_{0}, 1 \leqslant x_{i 1}+x_{i 2}+\ldots+x_{i a_{i}} \leqslant n_{\max } ;
\end{aligned}
$$

Where, $R_{s}, Q_{s}$ and $S_{s}$ refer to the system reliability, the open failure mode and the shorted failure mode probability respectively; C (i), W (i), Q (i), S (i) respectively refer to cost, weight, open failure and shorted failure probability of the subsystem; $\mathrm{C}_{0}$ and $\mathrm{W}_{0}$ refer to the cost and weight constraints of the system respectively; $x_{i j}$ refers to the number of parallel type $\mathrm{j}$ components in subsystem $\mathrm{i}$ (nonnegative integer); $\mathrm{q}_{\mathrm{ij}}$ and $\mathrm{s}_{\mathrm{ij}}$ refer to open failure and shorted failure probability of type $\mathrm{j}$ components in subsystem $\mathrm{i}$. The optimal problem is to determine the 
number of different types of components in the subsystem to meet system constraints (2.2) under the premise, and the system reliability (2.1) is maximum.

To facilitate the use of particle swarm optimization algorithm, set the particle (solution) structure as follows: $\quad X=\left[x_{11}, x_{12}, \cdots, x_{1 \mathrm{a}_{1}}, \cdots, x_{i 1}, x_{i 2}, \cdots, x_{i a_{i}}, x_{n 1}, x_{n 2}, x_{a_{n}}\right]$, that is, the system solution $\mathrm{X}$ is sequentially composted by each subsystem solutions array. Formula (2.2) shows that the feasible solution field has a very complex structure.

\section{Algorithm}

In the discrete particle swarm optimization algorithm with contraction coefficient, we use the following objective function:

$$
f(X)=R_{s}-M * \min \left(0, C_{0}-\sum_{i=1}^{n} C(i)\right)^{2}-M * \min \left(0, W_{0}-\sum_{i=1}^{n} W(i)\right)^{2} ;
$$

Where $\mathrm{M}$ is a sufficiently large positive integer numbe. The algorithm updates the velocity and the particle position according to Formulas (3.2) - (3.3) [13]:

$$
\begin{aligned}
& v_{i d}^{t+1}=\omega * v_{i d}^{t}+c_{1} * \operatorname{rand}() *\left(p_{i d}-x_{i d}^{t}\right)+c_{2} * \operatorname{rand}() *\left(p_{g t}-x_{i d}^{t}\right) ; \\
& x_{i d}^{t+1}=\left[x_{i d}^{t}+v_{i d}^{t}\right] ;
\end{aligned}
$$

in which, $[\mathrm{x}]$ is the integral function in Formula (3.2). MATLAB has function floor (x), fix (x), round (x), ceil (x) available. To solve the three-state S-P devices network RAP problem with cost and weight constraints and maximize the objective function, the particle swarm optimization algorithm is described as follows and the algorithm is a generalization of the corresponding Z.C.Wang's algorithm [13].

Algorithm

Step 0 Determine the population size $\mathrm{N}$, the maximum number of iterations $\mathrm{t}_{\max }$, inertia weight $\omega$, velocity constant $c_{1}, c_{2}$ and other parameters. Given the system shorted mode failure probability and open failure mode probability vector, the system cost constraints and weight constraint vector. Generate two groups of particle $X_{i}$ and $X{ }_{i}$, respectively, the location of particles and the particle's best historical location, the initial speed $v_{i}(i=1,2, \ldots, N)$, a global particle $\mathrm{P}$ (optimal position); using formula (2.1) to calculate corresponding reliability for each particle, determine whether they meet the cost and weight constraints, if not satisfied, it generates a new particle, until meet the constraints; according to the formula (3.1) to calculate the value of objective function.

Step1 If the value of the objective function of $X_{i}$ is greater than the objective function value of $X_{i}{ }_{i}$, replace $X_{i}$ with $X_{i}^{\prime}$; if objective function value of $X^{\prime}{ }_{i}$ is greater than objective function value of $\mathrm{P}$, use $\mathrm{X}^{\prime}{ }_{\mathrm{i}}$ instead of $\mathrm{P}$.

Step2 Update speed and particle position according to formula (3.2) - (3.3).

Step3 According to Formula (2.1) to calculate the reliability of each particle, determine whether to meet the cost and weight constraints, otherwise in accordance with Formula (3.2) (3.3) make adjustment until the constraint conditions is reached.

Step4 Calculate the objective function value of each particle. 
Step5 Determine the number of iterations $t$ whether it reaches the maximum number of iterations $\mathrm{t}_{\max }$; if yes, output the optimal solution, otherwise let $\mathrm{t}=\mathrm{t}+1$, turn to Step1.

Step6 End.

The convergence of the algorithm is discussed and proved by J.C.Zeng[14].

\section{Simulations}

\subsection{Example 1}

Assuming that the system consists of 3 subsystems in series, each subsystem is composed of 5 different types of components which are connected in parallel. The short failure probability $\mathrm{s}$ and the open failure probability $\mathrm{q}$, component cost $\mathrm{c}$ (Yuan) and component weight $\mathrm{w}(\mathrm{kg})$ are given in Table 1.

\begin{tabular}{ccccccccccccc}
\hline \multicolumn{10}{c}{ Table1 System Component Parameters } \\
\hline \multicolumn{10}{c}{ Subsystem 1 } & \multicolumn{10}{c}{ Subsystem 2 } & \multicolumn{7}{c}{ Subsystem 3 } \\
\hline & $\mathrm{s}$ & $\mathrm{q}$ & $\mathrm{c}$ & $\mathrm{w}$ & $\mathrm{s}$ & $\mathrm{q}$ & $\mathrm{c}$ & $\mathrm{w}$ & $\mathrm{s}$ & $\mathrm{q}$ & $\mathrm{c}$ & $\mathrm{w}$ \\
\hline 1 & 0.01 & 0.05 & 7 & 4 & 0.01 & 0.02 & 6 & 5 & 0.01 & 0.03 & 7 & 6 \\
2 & 0.01 & 0.08 & 6 & 6 & 0.01 & 0.13 & 3 & 7 & 0.01 & 0.1 & 6 & 8 \\
3 & 0.02 & 0.09 & 6 & 8 & 0.02 & 0.28 & 2 & 4 & 0.02 & 0.26 & 4 & 5 \\
4 & 0.02 & 0.23 & 3 & 7 & 0.04 & 0.3 & 2 & 7 & 0.04 & 0.25 & 3 & 4 \\
5 & 0.01 & 0.27 & 3 & 8 & 0.05 & 0.3 & 2 & 6 & 0.02 & 0.31 & 2 & 4 \\
\hline
\end{tabular}

Table1: System Component Parameters

Let $\mathrm{M}=100$ in Formula (3.1). With MATLAB2008a programming, the simulation on the computer (basic configuration is CPUTB960@2.2Ghz, 2.2Ghz, memory 4G, Windows 7 operating system). To take $\mathrm{n}=3, \mathrm{~N}=20, \mathrm{t}_{\max }=100, \mathrm{n}_{\max }=5, \mathrm{C}_{0}=30, \mathrm{~W}_{0}=53$; acceleration constant $\mathrm{c}_{1}=\mathrm{c}_{2}=1.4963$, weight $\omega$ linear reduced from 0.9 to 0.4 , that is, $\omega=0.9-0.5 *(\mathrm{t}-1) / 99$. The initial solution is selected as $(0,0,0,0,0|0,0,0,0,0| 0,0,0,0,0)$.

Random run 50 times, the optimal solution given by the algorithm is $(0,1,0,2,0|1,0,1,0,0|$ $0,0,0,0,5)$, the maximum reliability of the system $\mathrm{R}=0.9872$, the corresponding cost of $\mathrm{C}=30$ Yuan and weight $\mathrm{W}=49 \mathrm{~kg}$. The 50 runs give the maximum reliability as 0.9872 , the minimum reliability as 0.9735 , the average reliability of the system as 0.9833 and the total system operation time as 107.54699 seconds. See Fig. 1 for the reliability - iteration relation curve of the algorithm.

\subsection{Example 2}

As the system consists of 15 subsystems, each subsystems is composed of the same components, the short failure and open failure mode probability, cost c (Yuan) and weight $\mathrm{w}$ $(\mathrm{kg})$ of each subsystem components,. See Table 2.Let $\mathrm{M}=100$ in Formula (3.1). $\mathrm{R}_{\mathrm{s}}$ is given in Formula (4.1), where $\mathrm{s}_{\mathrm{i}}$ and $\mathrm{q}_{\mathrm{i}}$ refer to the shorted failure mode probability and the open failure mode probability respectively; $\mathrm{x}_{\mathrm{i}}$ refers to the components numbers of subsystem .

$$
R_{s}=\prod_{i=1}^{15}\left(1-q_{i}\right)^{x_{i}}-\prod_{i=1}^{15}\left(1-\left(1-s_{i}\right)^{x_{i}}\right) ;
$$

If the total cost of the system $\mathrm{C}_{0}<=400$ Yuan, the total weight of $\mathrm{W}_{0}<=414 \mathrm{~kg}, \mathrm{n}_{\max }<=6$. The parameters of the algorithm are as follows: $\mathrm{N}=20, \mathrm{t}_{\max }=300$, the inertia weight $\omega$ linear is reduced from 0.9 to 0.4 , the speed constant is $c_{1}=c_{2}=1.4963$, and the initial solution is 
$\mathrm{X} 0=[2,2,2,2,2,2,2,2,2,2,2,2,2,2,2]$. The optimal solution is $\mathrm{X}=[3,4,6,4,3,2,4,5,4,2,3,4,5,4,5]$. The maximum system reliability of corresponding is 0.9630 , the system costs RMB392 and the system weight is $414 \mathrm{~kg}$. See Fig. 2 for the reliability- iterative curve generated by the algorithm.

Upon random operation for 50 runs of the algorithm, the results show the maximum reliability is 0.9630 , the minimum reliability is 0.9282 , the average reliability is 0.9576 and the total time is 238.6807 seconds.

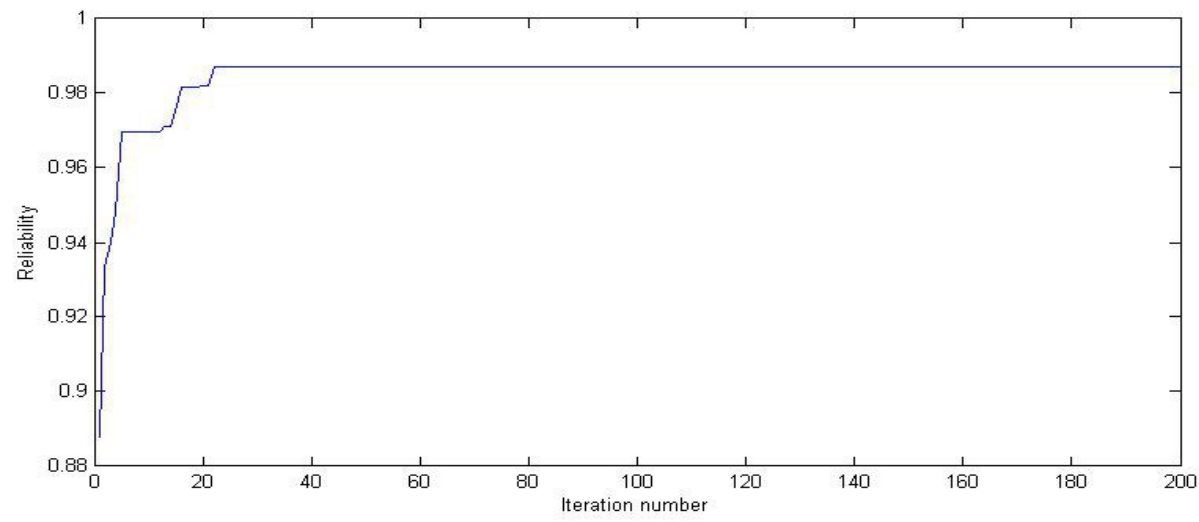

Figure 1: The Reliability - Iteration Relation Curve of Example1

\begin{tabular}{ccccc}
\hline \multicolumn{5}{c}{ Table 2 System Component Parameters } \\
\hline Subsystem No. & $\mathrm{s}$ & $\mathrm{q}$ & $\mathrm{c}$ & $\mathrm{w}$ \\
\hline 1 & 0.01 & 0.09 & 5 & 8 \\
2 & 0.01 & 0.24 & 4 & 9 \\
3 & 0.02 & 0.33 & 9 & 6 \\
4 & 0.02 & 0.18 & 7 & 7 \\
5 & 0.01 & 0.14 & 7 & 8 \\
6 & 0.01 & 0.06 & 5 & 8 \\
7 & 0.01 & 0.21 & 6 & 9 \\
8 & 0.02 & 0.32 & 9 & 6 \\
9 & 0.04 & 0.18 & 4 & 7 \\
10 & 0.05 & 0.04 & 5 & 8 \\
11 & 0.01 & 0.2 & 6 & 9 \\
12 & 0.01 & 0.22 & 7 & 7 \\
13 & 0.02 & 0.31 & 9 & 6 \\
14 & 0.04 & 0.17 & 8 & 5 \\
15 & 0.02 & 0.31 & 6 & 7 \\
\hline
\end{tabular}

Table 2:System Component Parameters

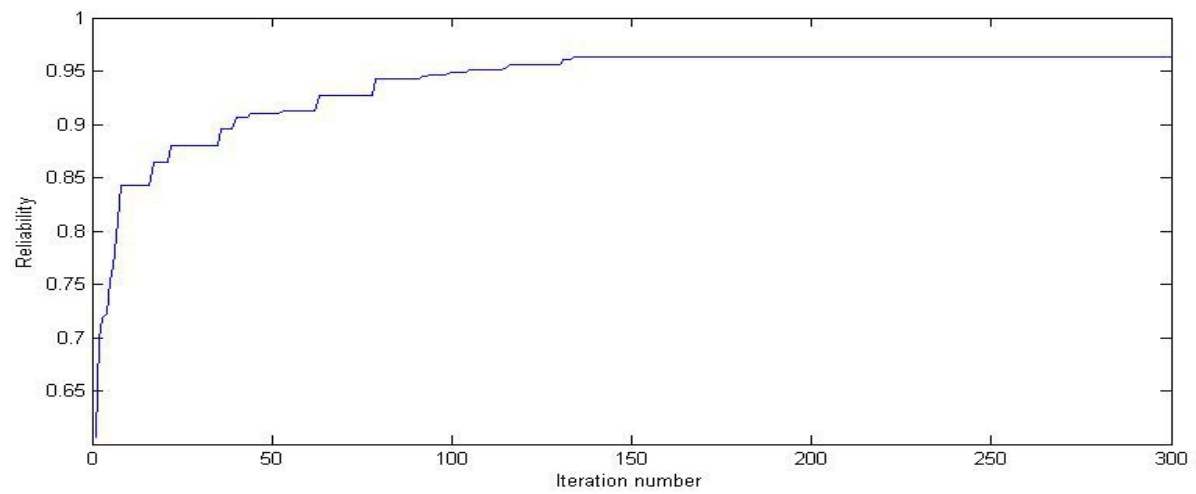

Figure 2: Reliability - Iteration Relation Curve of Example2 


\section{Convergence discussions}

In order to compare the effectiveness of the algorithm, the simulated annealing algorithm, genetic algorithm [8] and ant colony algorithm [9] are adopted to solve Examples1-2; the solution is shown in Table 3-4. In Table 3, although the ant colony algorithm [6] convergence is very good, the algorithm running time is too long. From the point of view that the best solution can be obtained, the convergence is good and the system time is less, the particle swarm optimization algorithm is better.

\begin{tabular}{|c|c|c|c|}
\hline & Genetic algorithm & Simulated annealing & Ant colony [9] \\
\hline Optimum solution & $(0,2,0,0,1|0,2,0,0,0| 0,0,0,0,4)$ & $(0,0,1,1,1|0,1,1,1,0| 1,0,1,0,0)$ & $(0,1,0,2,0|1,0,1,0,0| 0,0,0,0,5)$ \\
\hline Optimal solution reliability & $\mathrm{R}=0.9723$ & $\mathrm{R}=0.9758$ & $\mathrm{R}=0.9872$ \\
\hline Optimal solution cost & $\mathrm{C}=29$ yuan & $\mathrm{C}=30$ yuan & $\mathrm{C}=30$ yuan \\
\hline Optimal solution weight & $\mathrm{W}=50 \mathrm{~kg}$ & $\mathrm{~W}=52 \mathrm{~kg}$ & $\mathrm{~W}=49 \mathrm{~kg}$ \\
\hline $\begin{array}{l}\text { Random run times, } \\
\text { maximum reliability, } \\
\text { minimum reliability, } \\
\text { average reliability } \\
\text { and total run time }\end{array}$ & $\begin{array}{c}50 \text { times, } \\
0.9723, \\
0.9678 ; \\
0.9685, \\
6.1617 \mathrm{e}+03 \text { Seconds } \\
\end{array}$ & $\begin{array}{c}50 \text { times, } \\
0.9758, \\
0 ; \\
0.8650, \\
7.1219 \mathrm{e}+03 \text { Seconds }\end{array}$ & $\begin{array}{c}\mathrm{n}_{\max }=5 \text {, each operation } \\
\text { converges to the optimal } \\
\text { solution,one run } \\
\text { time is } \\
4677.391831 \text { Seconds }\end{array}$ \\
\hline Initial solution & $(0,2,0,0,0|0,2,0,0,0| 0,0,0,0,4)$ & $(0,0,0,0,0|0,0,0,0,0| 0,0,0,0,0)$ & $(1,1,1,1,1|1,1,1,1,1| 1,1,1,1,1)$ \\
\hline
\end{tabular}

Table 3: Ant Colony, Simulated Annealing and Genetic Algorithm Test Results for Example 1

\begin{tabular}{|c|c|c|c|}
\hline & Genetic algorithm & Simulated annealing & Ant colony [8] \\
\hline Optimum solution & $(3,3,5,3,3,3,3,5,3,3,5,5,5,3,5)$ & $(3,4,5,4,3|4,3,4,5,3| 3,4,4,3,5)$ & $(3,4,4,3,3|3,4,6,4,4| 3,3,4,5,4)$ \\
\hline Optimal solution reliability & $\mathrm{R}=0.9442$ & $\mathrm{R}=0.9401$ & $\mathrm{R}=0.9358$ \\
\hline Optimal solution cost & $\mathrm{C}=383$ yuan & $\mathrm{C}=370$ yuan & $\mathrm{C}=377$ yuan \\
\hline Optimal solution weight & $\mathrm{W}=412 \mathrm{~kg}$ & $\mathrm{~W}=414 \mathrm{~kg}$ & $\mathrm{~W}=410 \mathrm{~kg}$ \\
\hline $\begin{array}{l}\text { Random run times, } \\
\text { maximum reliability, } \\
\text { minimum reliability, } \\
\text { average reliability } \\
\text { and total run time }\end{array}$ & $\begin{array}{c}50 \text { times, } \\
0.9442, \\
0.9152, \\
0.9331, \\
247.0091 \text { Seconds }\end{array}$ & $\begin{array}{c}50 \text { times, } \\
0.9401, \\
0.8669, \\
0.9060, \\
9.7567 \mathrm{e}+03 \text { Seconds }\end{array}$ & $\begin{array}{c}\text { 50times, } \\
0.9358, \\
0.8610, \\
0.8974, \\
591.670214 \text { Seconds }\end{array}$ \\
\hline Initial solution & $(4,4,4,4,4,4,4,4,4,4,4,4,4,4,4)$ & $(3,3,3,3,3|3,3,3,3,3| 3,3,3,3,3)$ & $(1,1,1,1,1|1,1,1,1,1| 1,1,1,1,1)$ \\
\hline
\end{tabular}

Table 4:Ant Colony, Simulated Annealing and Genetic Algorithm Test Results for Example2

\section{Conclusion}

For three-state devices S-P network reliability redundancy allocation problem (RAP), when the components of the system are more complex, or the number of subsystems is more, the particle swarm optimization algorithm in convergence performance (convergence curve) is very good and is less in the execution time of algorithm.

\section{References}

[1]G.Mitsuo, Y. S.Yun. Soft computing approach for reliability optimization: state-of-the-art survey [J]. Reliability Engineering \& System Safety.2006, 91(09):1008-1026

[2] D. W.Coit, A.E.Smith. Reliability optimization series-parallel using a genetic algorithm

[J].IEEE Transations, 1996, 45(01):254-260+266

[3]K.B.Misra. An efficient algorithm to solve integer-programming problems arising in systemreliability Design [J]. IEEE Transations, 1991, 40(01):81-91 
[4]J.A.Michel. A simplified approach for reliability evaluation and component allocation in threestate series and parallel systems composed of non-identical components [J]. Gest. Prod. Sao Carlos. 2009, 16(01):54-62

[5]L.Page, J.Perry. Optimal "series-parallel” networks of 3-state devices [J]. IEEE Transitions, 1988, 37(04): 388-394

[6]G.G.C.Walter, A.R.Pelug. Configurations of series-parallel networks with maximum reliability [J]. Microelectronics and Reliability, 1996, 36(02): 247-253

[7] G.Levitin. Optimal series-parallel topology of multi-state system with two failure modes [J]. Reliability Engineering \& System Safety, 2002a, 77(01):93-107

[8]S.Gao, J.Y.Yang, X.J.Wu, T.M.Liu. Ant colony optimization algorithm for reliability [J]. Journal of computer applications and software, 2004,21(12):94-96(In Chinese)

[9]S.J.Cheng,P.Lu,P.He. Application of ant colony algorithm in reliability redundant allocation [J].Journal of computer engineering and Applications,2009,45(15):64-66(In Chinese)

[10]Q.Chen, X.Y.Ma. Ant colony algorithm for solving the problem of spare parts allocation in serial-parallel system $[\mathrm{J}]$. Journal of modular machine tools and automation technology, 2010, 52(04):49-51+55(In Chinese)

[11]Z.J.Xu, C.W.Ma, Q.Z.Mei, S.R.Xi. A genetic algorithm for solving a system reliability optimization problem [J]. Journal of Tsinghua University (Natural Science Edition), 1998, 38(07):54-57(In Chinese)

[12]H.Garg,S.P. Sharma. Multi-objective Reliability-redundancy Allocation Problem using Particle Swarm Optimization [J]. Computers \& Industrial Engineering, 2013, 64(01):247-255

[13]Z.C.Wang,W.W.Li. Reliability optimization based on particle swarm optimization [J]. Journal of Taizhou University, 2006,28(06):29-32(In Chinese)

[14]J.C.Zeng,J.Jie,Z.H.Cui. Particle swarm optimization algorithm [M].Beijing:Science Press,2004 (In Chinese)

[15]Wulantuya, D.K.Li, Qimuge. A reliability optimization model for non-identical components in parallel [J]. Journal of Inner Mongolia Normal University (Natural Science Edition), 2015, 44(06):761-764(In Chinese)

[16]Wulantuya, Qimuge, D.K.Li . Reliability optimization of 3-tate devices network with single objective and single constraint [J]. Journal of Inner Mongolia Normal University (Natural Science Edition), 2015, 44(04):439-442. (In Chinese)

[17]M.Feizabadi, A.E.Jahromi. A new model for reliability optimization of series-parallel systems with non-homogeneous components [J]. Reliability Engineering \& System Safety, 2016, 157:101112

[18]J.J.Liu . System reliability optimization based on particle swarm optimization algorithm [J]. Journal of computer and digital engineering, 2012,40(04):6-7+14 (In Chinese)

[19]M.Aghaei, A.Z.Hamadani,M.A. Ardakan. Redundancy allocation problem for $k$-out-of- $n$, systems with a choice of redundancy strategies[J]. Journal of Industrial Engineering International, 2017,13(01):81-92

[20]D.K.Li, D.Hai. Research on reliability optimization of S-P networks with non- identical components in parallel [J]. Yinshan Academic Journal (Natural Science Edition), 2016, 30(02):3541 (In Chinese) 